STUDI

FRANCESI

\section{Studi Francesi}

Rivista quadrimestrale fondata da Franco Simone

145 (XLIX | I) | 2005

Varia - fasc. I - gennaio-aprile 2005

\title{
"Comme mon coeur désire». Guillaume de Machaut, Le Livre du Voir Dit, études réunies par Denis Hüe
}

\section{G. M. Roccati}

\section{(2) OpenEdition}

1 Journals

\section{Édition électronique}

URL : http://journals.openedition.org/studifrancesi/35691

DOI : 10.4000/studifrancesi.35691

ISSN : 2427-5856

Éditeur

Rosenberg \& Sellier

\section{Édition imprimée}

Date de publication : 1 juillet 2005

Pagination : 130-131

ISSN : 0039-2944

\section{Référence électronique}

G. M. Roccati, « «Comme mon coeur désire». Guillaume de Machaut, Le Livre du Voir Dit, études réunies par Denis Hüe », Studi Francesi [En ligne], 145 (XLIX | I) | 2005, mis en ligne le 30 novembre 2015, consulté le 18 avril 2021. URL : http://journals.openedition.org/studifrancesi/35691 ; DOI : https:// doi.org/10.4000/studifrancesi.35691

Ce document a été généré automatiquement le 18 avril 2021.

\section{(c) 98}

Studi Francesi è distribuita con Licenza Creative Commons Attribuzione - Non commerciale - Non opere derivate 4.0 Internazionale. 


\title{
"Comme mon coeur désire». Guillaume de Machaut, Le Livre du Voir Dit, études réunies par Denis Hüe
}

\author{
G. M. Roccati
}

\section{RÉFÉRENCE}

«Comme mon coeur désire». Guillaume de Machaut, Le Livre du Voir Dit, études réunies par Denis Hüe, préface par Jacqueline Cerquiglini-Toulet, Orléans, Paradigme («Medievalia», 38), 2001, pp. 282.

1 Le volume rassemble quinze articles en grande partie déjà parus, mais la moitié d'entre eux environ sont ici en traduction française inédite; tous concernent le Voir Dit, à des titres divers, reflétant la richesse de l'oeuvre de Machaut. J'indique sommairement entre parenthèses les références des premières parutions.

Georg HANF, Sur le «Voir Dit» de Guillaume de Machaut, pp. 7-61 (paru en allemand: «Zeitschrift für romanische Philologie», 1898). G. B. GYBBON -MONNYPENNY, L'«autobiographie» amoureuse de Guillaume de Machaut. Les précurseurs de la forme du «Voir Dit», pp. 63-82 (paru en anglais: Mélanges Fr. Whitehead, 1973). Sarah Jane WILLIAMS, La dame, les chansons et les lettres, pp. 83-92 (paru en anglais: «Early Music», 1977). Kevin BROWNLEE, L'oeuvre poétique de Guillaume de Machaut. Identité du discours et discours de l'identité, pp. 93-107 (paru en anglais: Machaut's World..., éd. M. Pelner Cosman, 1978). William CALIN, Problèmes de technique narrative au Moyen Âge. Le «Roman de la Rose» et Guillaume de Machaut, pp. 121-132 («Senefiance», 1979). Friedrich WOLFZETTEL, La poésie lyrique en France comme mode d'appréhension de la réalité. Remarques sur l'invention du sens visuel chez Machaut, Froissart, Deschamps et Charles d'Orléans, pp. 157-172 (Mélanges Ch. Foulon, 1980). Daniel POIRION, Le monde imaginaire de Guillaume de Machaut, pp. 173-186 (Guillaume de Machaut, poète et compositeur, 1982). Maureen Boulton, L'idéologie de la forme. Le «Voir Dit» de Guillaume de Machaut, pp. 199-207 (paru en anglais: Courtly 
Literature..., 1990). Sarah Jane WiLliAms, Les pièces lyriques dans le «Voir Dit» de Guillaume de Machaut, «voir» et «veoir», pp. 209-219 (paru en anglais: «Ars Lyrica», 1993). Catherine ATTWOoD, Temps et lieux de Souvenir. Le «Voir Dit» de Guillaume de Machaut, pp. 235-256 (inédit). Nicole Elise LASSAHN, Vérité historique et vérité fictionnelle dans le "Voir Dit» de Guillaume de Machaut, pp. 257-280 (traduction d'une communication présentée à Kalamazoo, 2000).

Outre la préface, trois articles sont de Jacqueline CERQUIGLINI-TOULET: Tension sociale et tension d'écriture au XIV ${ }^{\mathrm{e}}$ siècle. Les «dits» de Guillaume de Machaut, pp. 109-119 (Littérature et société..., éd. D. Buschinger, 1978); Le clerc et l'écriture. Le "Voir Dit» de Guillaume de Machaut et la définition du «dit», pp. 133-156 (GRLMA, Literatur in der Gesellschaft..., 1980); Le clerc et le louche. Sociologie d'une esthétique, pp. 187-198 (paru en anglais: «Poetics today», 1984); Polyphème ou l'antre de la voix dans le «Voir Dit» de Guillaume de Machaut, pp. 221-234 (Mélanges D. Poirion, 1995). 